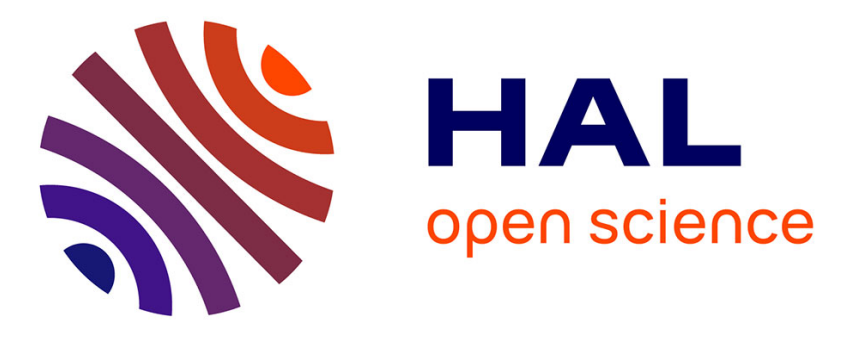

\title{
Temperature influence on electromagnetic measurements of concrete moisture
}

Sylvain Chataigner, Jean-Luc Saussol, Xavier Derobert, Géraldine Villain, Christophe Aubagnac

\section{- To cite this version:}

Sylvain Chataigner, Jean-Luc Saussol, Xavier Derobert, Géraldine Villain, Christophe Aubagnac. Temperature influence on electromagnetic measurements of concrete moisture. European Journal of Environmental and Civil Engineering, 2015, 19 (4), pp.482-495. 10.1080/19648189.2014.960102 . hal-01207702v2

\section{HAL Id: hal-01207702 \\ https://hal.science/hal-01207702v2}

Submitted on 25 Sep 2017

HAL is a multi-disciplinary open access archive for the deposit and dissemination of scientific research documents, whether they are published or not. The documents may come from teaching and research institutions in France or abroad, or from public or private research centers.
L'archive ouverte pluridisciplinaire HAL, est destinée au dépôt et à la diffusion de documents scientifiques de niveau recherche, publiés ou non, émanant des établissements d'enseignement et de recherche français ou étrangers, des laboratoires publics ou privés. 


\title{
TEMPERATURE INFLUENCE ON ELECTROMAGNETIC MEASUREMENTS OF CONCRETE MOISTURE
}

\author{
Sylvain CHATAIGNER*, Jean-Luc SAUSSOL**, Xavier DEROBERT*, Géraldine
} VILLAIN*, Christophe AUBAGNAC**

* Université LUNAM, IFSTTAR, Department Materials and Structures, Route de Bouaye, 44344 BOUGUENAIS, France.

sylvain.chataigner@ifsttar.fr (corresponding author)

** Département Laboratoire d'Autun, CETE de Lyon, CEREMA, Bd de Saint Andoche, 71400 AUTUN, France.

\begin{abstract}
In order that non destructive testing methods become quantitative tools for structure owners, it is needed to assess their precision and sensitivity to the environment. The presented study deals with two electromagnetic methods classically used to survey road pavements and concrete structures: a radar technique and a capacitive technique. The presented investigations aim at assessing the influence of temperature and moisture on the two methods for measurements realized on concrete slabs. The temperature was ranging from $5^{\circ} \mathrm{C}$ to $45^{\circ} \mathrm{C}$ and the surrounding relative humidity $(\mathrm{RH})$ evolved between $60 \%$ and $90 \%$. The study is part of a more ambitious topic aiming at defining quantitative non destructive methods to evaluate the water content of concrete structures on site and their state of degradation. The presented work allows assessing the sensitivity of both radar and capacitive techniques to the environmental
\end{abstract}


conditions: temperature and relative humidity. Moreover, the measurement variability of the used capacitive probes with three different sets of electrodes is estimated.

\section{Key Words}

Concrete - Non Destructive Testing - Temperature - Moisture - Electromagnetic measurements

\section{INTRODUCTION}

There is an important need in non destructive testing methods in the field of civil engineering to help in establishing precise diagnoses. These methods should be on the disposal of structure owners and would clearly contribute to an optimization of the structure management processes.

Among non destructive methods, it has been proved that the electromagnetic ones are sensitive to concrete durability indicators such as water content, chloride content, and porosity to a lesser extent [1-8]. Several studies on relative permittivity for different concrete have indeed shown that sensitivity levels were important on large frequency bands (larger that the radar ones) [2, 9-13]. These works have also demonstrated that other parameters could influence the permittivity measurements, such as the type of aggregate, the quantity and nature of finer particles $(<80 \mu \mathrm{m})$ and the nature of the used cement.

Consequently, several researchers decided to use other non destructive methods modifying the frequency spectra [14-15], using mechanical means and combining several non destructive testing [16-18], to decorrelate uncertainties in order to get quantitative data. However, many additional studies are still necessary before traditional destructive on site methods may be replaced by non destructive investigations [19-22]. In particular, to assess accurately 
volumetric water content $\mathrm{W}$ and water content gradient by means of permittivity measurements on site, it is necessary to determine the influence of environmental conditions such as temperature and eventually to correct its effect.

One of the needed steps for this is presented in this article and consists in analyzing the permittivity measurement and the assessment of water content on concrete slabs with two electromagnetic methods: radar, and capacitive technique. The aim is to quantify the evolution of the permittivity with temperature $\mathrm{T}$ depending on three stabilized volumetric water content W.

In the first part, the used experimental protocol is described: the samples and the means used to control temperature and moisture. The second part focuses on the radar technique for high frequency ( $>2 \mathrm{GHz}$ ), and the obtained experimental results. The last part presents the results obtained by the capacitive technique working at frequencies around $30-35 \mathrm{MHz}$. For this second method, repeatability measurements have also been carried out.

\section{EXPERIMENTAL PROTOCOL}

In order to study the influence of temperature on these non destructive measurements, samples were realized using a classical mix design in civil engineering. The relative humidity (RH) and the temperature (T) of the samples were imposed thanks to a hydro climatic chamber and controlled by weighing and embedding thermo-hygrometric probes in a witness slab (A)

\subsection{Samples realization and description}

In addition to the witness slab A, two concrete slabs were cast at the same time and used for the study (slabs B and C). The used cement is a Portland cement CEM I $52.5 \mathrm{~N}$ with $385 \mathrm{~kg}$ of cement per cubic meter. The used aggregates were silica, the concrete was vibrated using a needle vibrator and the cure of the slabs was carried out at $20^{\circ} \mathrm{C}$ in water tanks during 28 
days. The obtained concrete can be classified as C35: this was checked by compressive tests at 28 days.

Slab A dimensions are the following: 200x140x120 mm3. Three thermo-hygrometric probes were embedded at three different heights $(40,60$ and $80 \mathrm{~mm})$ and the lateral slab faces were tight by adhesive aluminium foil to guaranty unidirectional drying [23]. Slab B dimensions are the following: 450x300x120 mm3 (the water intake was followed weighing additional slabs cast at the same time with the same mix). Slab C dimensions are the following: 280x280x120 mm3 (in that case, water intake was followed weighing the slab).

Carbonation measurements, resistivity measurements and water porosity measurements were carried out on slab B to characterize the concrete according to the recommended protocols by French Civil Engineering Association [24,25]. A maximal carbonated depth of $3.4 \mathrm{~mm}$ was determined using phenolphthalein with $1 \%$ alcohol. The average water porosity proved to be $13.4 \%$ and the average resistivity $79^{\prime} \Omega . m[21]$.

\subsection{Humidity and temperature control}

In a first preconditioning step, slabs were dried in a climatic chamber at $60{ }^{\circ} \mathrm{C}$ and $\mathrm{RH}=60 \%$ during several weeks until the mass stabilization (mass intake was less than $0.05 \%$ of the sample mass between two successive weighing (delay equal to $24 \mathrm{~h}$ ) [25]. The slabs were then considered as homogeneous, which is confirmed by RH sensors embedded at various depths in slab A.

At this stabilized relative humidity of $60 \%$, a complete thermal cycle including electromagnetic investigations was performed. This is detailed in paragraph 2.3.

In the following steps, for each relative humidity condition (80 and 90\%), the one-month preconditioning step and an identical complete thermal cycle were done. 
The control is made by weighing the concrete slab. The water contents obtained at the end of each preconditioning step are given in table 1 . Both massic and volumetric water contents were determined in order to address both communities specialized in electromagnetism and concrete durability.

During the thermal cycle designed to obtain homogeneous temperature inside the slab, the internal RH is kept constant. Each thermal increment is sufficiently short to consider that the slab water content remains constant. This hypothesis is even more consistent that the concrete porosity is low $(13.5 \%)$.

\subsection{Thermal cycle protocol and electromagnetic measurements}

For each of the studied relative humidity situation, after reaching the stabilisation in mass, the measurements at different temperature steps were carried out as shown on figure 1 . The realized thermal cycle allowed us to investigate five different temperatures $\left(5^{\circ} \mathrm{C}, 15^{\circ} \mathrm{C}, 25^{\circ} \mathrm{C}\right.$, $35^{\circ} \mathrm{C}$ and $45^{\circ} \mathrm{C}$ ). As an increase during one week and a decrease during the following week were performed, it enables studying the reversibility of the observed phenomena.

The measurements were carried out in a stabilized tempered local $\left(20^{\circ} \mathrm{C}\right)$ as soon as the slabs were removed from the chamber in order to avoid any bias from the NDT systems on the measurements.

\section{INFLUENCE OF THE TEMPERATURE IN THE CASE OF THE RADAR}

\subsection{Measurement protocol for the radar}

The studied radar is classically used for road survey or rebar detection within reinforced concrete. It has a characteristic central frequency of $2.6 \mathrm{GHz}$ (Figure 2). Both transmission and reception antenna are disposed close to each other $(40 \mathrm{~mm})$ on a specific trolley equipped 
with a turn and push system. The received signals are recorded with a SIR 20 system (manufacturer GSSI) and processed with a commercial software (RADAN from GSSI).

Before each measurement campaign, a measurement in the air is performed in order to get a reference of "time zero". For each measurement, four types of profiles have been realized: two dynamic ones in two principal directions, and two static ones in the middle of the slab (one profile with no average, and one with an average on 32 measurements). The slab is situated on top of a steel plate.

For each profile, three results are determined:

- the ratio of the amplitude of the direct wave propagating on the slab surface to the amplitude of the direct wave propagating in the air ;

- the ratio of the amplitude of the reflected wave on the bottom of the slab to the amplitude of the direct wave propagating in the air;

- the travel time of the reflected wave during its propagation within concrete.

An example of obtained radar profile is given in figure 3. The analysis of these profiles consists in picking the different arrival times (green or red in the figure) in the reflexion zones. It can be checked that, in the medium zone, the signal is not affected by edge effects that are clearly visible elsewhere. The use of a turn and push system allows validating the work zone for the amplitudes.

\subsection{Investigation results}

The results for the longitudinal profile and for the three humidity conditions are given in figures 4 and 5 (a good reversibility was observed and is included in the error bars). Figure 6 consists in another representation of the figure 4 .

For the other profiles, similar observations were done: 
- The amplitude value of the received signal decreases a little with the temperature in the case of the direct wave as well as in the case of the reflected wave,

- The propagation time increases a little with temperature,

- The influence of humidity seems to remain low for the three studied results,

- Thanks to travel time, the concrete relative permittivity can be simply calculated by assuming that the concrete slab is homogenous so that its permittivity is constant. The concrete relative permittivity of concrete increases of about $10 \%$ for a temperature increase of $40^{\circ} \mathrm{C}$. This corresponds to an order of magnitude of $2.5 \%$ increase per $10^{\circ} \mathrm{C}$ for a classical concrete mix design.

- More practically, the permittivity evolution may also be related to an error in the assessment of the concrete thickness of $5 \%$ for a temperature increase of $40^{\circ} \mathrm{C}$. It can be noted that the range of $40^{\circ} \mathrm{C}$ is classically encountered on site between winter and summer periods.

- It can be noted that the measurements of the direct wave propagating on the slab surface seem to be the most consistent regarding the relative humidity variations. This may be attributed to small differences between the two used slabs that may have slightly different thicknesses or different carbonation state. Results in terms of reflected wave and travel time may be affected by such parameters.

The results concerning the obtained slopes for the three measurements are given in table 2 .

\section{INFLUENCE OF TEMPERATURE ON THE MEASUREMENTS PERFORMED WITH THE CAPACITIVE TECHNIQUE}

\subsection{Measurement protocol for the capacitive technique}

The capacitive technique consists in the measurement of the resonance frequency of an oscillating system between $30-35 \mathrm{MHz}$ and between two metallic electrodes disposed on the surface of the studied concrete [26-29]. It can be considered that these electrodes form with 
the studied material a dielectric capacitor. Its capacity (in Farad) depends on the electrode geometry and the relative permittivity $\varepsilon_{\mathrm{r}}$ of the studied material. Practically, the resonance frequency may vary depending on concrete mix mainly linked with water intake, aggregate nature, and cement content. The used capacity probes have three different types of electrodes: large electrodes LE ( 2 metallic plates of 70 x $40 \mathrm{~mm}^{2}$ spaced from $40 \mathrm{~mm}$ ), middle or average size electrodes $\mathrm{AE}$ (4 metallic plates of $70 \times 10 \mathrm{~mm}^{2}$ spaced from $10 \mathrm{~mm}$ ), and small electrodes SE (5 metallic plates of $70 \times 5 \mathrm{~mm}^{2}$ space from $5 \mathrm{~mm}$ ) (figure 7). The used electrode size influences the depth of investigation that may vary from several millimetres in the case of the small electrodes to 6-7 centimetres in the case of the large electrodes. This particularity enables us assessing water content gradients versus the slab depth.

As for the radar procedure, a measurement in the air is realized before each measurement campaign and the difference between the resonance frequencies is studied.

A calibration has been carried out on reference materials - teflon, PVC, granite, marble and limestone (whose permittivity have been determined using electromagnetic cell [12]) - for the three different type of electrodes. The results show linear relationship between resonance frequency and relative permittivity (figure 8). The investigations have been performed in two cases: with or without steel plate under the samples. Similar results have been obtained.

The obtained results will allow us to determine the average relative permittivity of the studied concrete for a zone depending on the depth of investigation (type of electrode). This should thus also give an insight on possible gradient due for instance to moisture or to skin effect. Before the realization of the experimental investigations, the measurement variability and the edge effects have been assessed [20]. Two examples of the obtained results are given in figure 9. The first one is a histogram representing the repeatability of the measurements for one of the slab from 120 measurements $(9$ a). The second one represents the influence of the edge effect depending on the type of electrode that is used and their orientation (9b). 
These investigations show that:

- the border effect is more important when using large electrodes and measurements should be performed at $7 \mathrm{~cm}$ from the slab edge so that results are not disturbed by this phenomena (evolution of the permittivity inferior to 0.1 );

- in the case of the capacitive technique, the repeatibility decreases when the size of the electrodes decrease. This is certainly due to the quality of the contact zone between the electrode and the concrete slab which is momentous when the size of the investigated zone is small (as it is the case for the small electrodes);

- the repeatibility of the method itself (30 measurements on a same point) proved to be really good; standard deviation is equal to 0.04 for the large electrodes, 0.07 for the average ones and 0.14 for the small ones for permittivity [20];

- the repeatability of the method associated to the material dispersion (120 measurements realized in different points of the slab at at least $7 \mathrm{~cm}$ from the slab edge) proved to be much more important: standard deviation is 0.61 for large electrodes, 1.48 for the average ones, and 0.9 for the small ones for permittivity [20].

For the rest of the investigations, for each studied value, three measurements were carried out in three different points in the middle of the slab so that the results are not affected by edge effects. The measurement points have been identified in order to reduce and neglect the dispersion associated with the material.

\subsection{Investigation results}

The results are given in figures 10, 11 and 12. For each figure, the represented data corresponds to an average of the realized measurements (a good reversibility was observed and is taken into account in the error bar). The straight lines are the regression curves linking 
permittivity to temperature for the different studied relative humidities. For the realized investigations, the obtained slopes have been determined and are given in table 3 .

It can be noted that the dependence of the permittivity with temperature seems to be linear and highly dependent on humidity (correlation coefficients $\mathrm{R}^{2}$ are close to 1 ) in accordance with literature $[27,12,17]$.

Between the two extremes, the permittivity evolves from 0.43 per $10^{\circ} \mathrm{C}$ to 0.8 per $10^{\circ} \mathrm{C}$. This corresponds to errors of respectively $6 \%$ per $10^{\circ} \mathrm{C}$ and $9 \%$ per $10^{\circ} \mathrm{C}$ that could be made in the assessment of concrete permittivity on site. This is superior to what was observed in the case of the radar method.

This means that practically, the dependence of the measurements to temperature and humidity can not be ignored in case of monitoring a structure on site.

In this perspective, a complementary experiment has been performed studying the effect of the temperature on the NDT systems themselves through measurements on a stable tempered concrete slab. Testing $20^{\circ} \mathrm{C}$ of variation of temperature on the radar and capacitive systems did not reveal any shift in the measurements due to the temperature of the systems themselves.

It is also interesting to note that permittivity results depend on the size of the used electrodes. This may be due to the heterogeneity of the concrete material and to its characteristic dimension (which is the size of the maximum aggregate diameter), to skin effects, or to imperfections of the calibration process. It seems thus difficult to adopt the absolute permittivity without correction as a quantitative parameter.

\section{CONCLUSION}

This article aimed at assessing the influence of temperature on concrete water content assessment using electromagnetic measurement techniques. Two methods were investigated: 
the radar and the capacitive technique, using three different sizes of electrodes, working in two different frequency bands: around $2 \mathrm{GHz}$ and $33 \mathrm{MHz}$ respectively. The studied concrete is classically used in civil engineering structures. It is important to note that the observed results are available for the studied concrete that has a rather low porosity.

The realized investigations allow showing the sensitivity of the concrete permittivity to the two parameters ( $\mathrm{T}$ and $\mathrm{W}$ ). The dependence of the permittivity on the temperature is linear for the two methods: radar (around $2 \mathrm{GHz}$ ) and capacitive method (at $33 \mathrm{MHz}$ ). This one can thus be assessed through experimental calibration. The dependence of the permittivity on moisture does not seem to be very important in the case of the radar measurements. On the contrary, this influence seems to be important in the case of the capacitive technique and highly coupled with the effect of temperature. Table 4 summarizes the observations for both methods.

For both non destructive methods, temperature and humidity increase tend to increase the measured permittivity. The effect of these two parameters should be taken into account when carrying on site measurements. This can be done using a similar experimental calibration process than the one proposed here with concrete samples from the studied structure. For a close concrete mix design (low porosity), a calibration of the temperature effect alone should be sufficient in the case of radar investigations. A coupled calibration of both temperature and moisture effect will have to be undergone in the case of the capacitive technique.

\section{BIBLIOGRAPHY}

[1] Soutsos, M. N., Bungey, J. H., Millard, S. G., Shaw, M. R., Patterson, A. (2001). Dielectric properties of concrete and their influence on radar testing. NDT\&E International, 34(6), 419-425. 
[2] Laurens, S., Balayssac, J.P., Rhazi, J., Arliguie, G. (2002). Influence of concrete moisture upon radar waveform, RILEM Materials and Structures, 35(248), 198-203.

[3] Klysz, G., Balayssac, J P. (2007). Determination of volumetric water content of concrete using ground-penetrating radar. Cement and Concrete Research. 37(8), 1164-1171.

[4] Laurens, S., El Barrak, M., Balayssac, J.P., Rhazi J. (2007). Aptitude of the near-field direct wave of ground-coupled radar antennas for the characterisation of the coverconcrete. Construction and Building Materials, 21( 12), 2072-2077

[5] Hugenschmidt, J., Loser, R. (2008). Detection of chlorides and moisture in concrete structures with ground penetrating radar. Materials and Structures, 41(4), 785-792.

[6] Kalogeropoulos, A., Van der Kruk, J., Hugenschmidt, J., Busch, S., Merz, K. (2011). Chlorides and moisture assessment in concrete by GPR full waveform inversion. Near Surface Geophysics, 9, 277-286.

[7] Méthode d'essai LPC $N^{\circ} 58.12$ Détermination des profils de teneur en eau dans les bétons par sondes capacitives.

[8] Villain, G., Derobert, X., Abraham, O., Coffec, O., Durand, O., Laguerre, L., Baltazart, V., Use of ultrasonic and electromagnetic NDT to evaluate durability monitoring parameters of concrete, $7^{\text {th }}$ International Symposium on Non Destructive Testing in Civil Engineering NDTCE’09, Nantes, France, 30 June-3 july 2009, p.343-348.

[9] Bois, K., Benally, A., Nowak, P., and Zoughi, R. (1997). Microwave nondestructive determination of sand to cement $(\mathrm{s} / \mathrm{c})$ ratio in mortar. IEEE Transactions on Instrumentation and Measurement, 9, 227-238.

[10]Robert A. (1998). Dielectric permittivity of concrete between $50 \mathrm{MHz}$ and $1 \mathrm{GHz}$ and GPR measurements for building materials evaluation. Journal of Applied Geophysics, 40, 89-94, 
[11]Lai, W., Kou, S., Tsang, W., and Poon, C. (2009). Characterization of concrete properties from dielectric properties using ground penetrating radar. Cement and Concrete Research, 39, 687-695.

[12]Derobert, X, Villain, G, Cortas, R, Chazelas, J.L. EM characterization of hydraulic concretes in the GPR frequencyband using a quadratic experimental design, $7^{\text {th }}$ International Symposium on Non Destructive Testing in Civil Engineering NDTCE'09, Nantes, France, 30 June-3 july 2009. 177-182.

[13]Ihamouten, A., Chahine, K., Baltazart, V., Villain, G., and Dérobert, X. (2011). On variants of the frequency power law for the electromagnetic characterization of hydraulic concrete. IEEE Transactions on Instrumentation and Measurement, 60(11), 3658-3668.

[14] Sbartaï, Z. M. , Laurens, S., Rhazi, J., Balayssac, J. P., Arliguie, G. (2007). Using radar direct wave for concrete condition assessment: Correlation with electrical resistivity. Journal of Applied Geophysics, 62(4), 361-374.

[15] Villain, G., Ihamouten, A., Dérobert, X. (2011), "Use of frequency power law to link the results of two EM testing methods for the characterization of humid concretes", IWAGPR'2011 cong. Proc., Aachen (GE).

[16]Balayssac, J.-P., Laurens, S., Arliguie, G., Breysse, D., Garnier, V., Derobert, X., Piwakowski, B. (2012). Description of the general outlines of the French project SENSO - Quality assessment and limits of different NDT methods, Construction and Building Materials, 35, 131-138. http://dx.doi.org/10.1016/j.conbuildmat.2012.03.003

[17]Breysse, D., Klysz, G., Derobert, X., Sirieix, C., Lataste, J.F. (2008). How to combine several non-destructive techniques for a better assessment of concrete structures, Cement and Concrete Research, 38, 783-793

[18] Villain, G., Sbartaï, Z. M., Derobert, X., Garnier, V., Balayssac, J.-P., (2012). Durability diagnosis of a concrete structure in a tidal zone by combining NDT methods: laboratory 
tests and case study, Construction and Building Materials, 37, 893-903. http://dx.doi.org/ 10.1016/j.conbuildmat.2012.03.014

[19]Lamarre A.S., Saussol J.L., Chataigner S., Measurement methods description and used protocols, Report, In French, CETE Lyon, Janvier 2011.

[20]Lamarre A.S., Saussol J.L., Chataigner S., Assessment of the measurement variabilities : edge effect, variability of the material alone, variability of the measuring tools, Report, In French CETE Lyon, Février 2011.

[21]Lamarre A.S., Saussol J.L., Chataigner S., OR11R075 : Non destructive measurements on concrete in different relative humidities and temperatures: capacitive probes, and radar, Report, In French, CETE Lyon, Février 2011.

[22] Saussol J.L., Rabasse M., Aubagnac C.., Concrete characterization of the slabs used for non destructive investigations in OR 11R075, Report, In French, CETE Lyon, Février 2012.

[23] Khelidj, A., Bastian, G., Baroghel-Bouny, V., Villain, G. (2007). Experimental study of the evolution of heat and moisture transfer parameters of a concrete slab, Magazine of Concrete Research, 59(5), 377-386.

[24]Mode opératoire recommandé par l'AFPC-AFREM, Compte-rendu des Journées Techniques AFPC-AFREM "Durabilité des bétons", 11 et 12 décembre 1997, Toulouse, $283 p$.

[25] Baroghel-Bouny V. et al. Concrete design for a given structure service life - Durability management with regard to reinforcement corrosion and alkali-silica reaction - State of the art and guide for the implementation of a predictive performance approach based upon durability indicators, Scientific and technical documents AFGC, 2007, 252 p.. 
[26] Taillade, F., Cottineau, L.M., Aubagnac, C., 'Capacitive probe for non destructive inspection of external post-tensioned ducts', Review of progress in quantitative non destructive evaluation, AIP Conference Proceedings 1096 (2009) 1512-1519.

[27]Derobert, X., Iaquinta, J., Klysz, G., Balayssac, J.P., (2008). Use of capacitive and GPR techniques for the non destructive evaluation of concrete cover. NDT \& E International, 41(1), 44-52.

[28]Derobert, X. (2010). Capacimetry. In: Non-destructive evaluation of reinforced concrete structures, volume 2. Woodhead Publishing Lim., Cambridge (UK).

[29]Du Plooy, R., G. Villain, G., Palma Lopes, S., Ihamouten, A., Derobert, X., Thauvin, B., Electromagnetic non-destructive evaluation techniques for the monitoring of water and chloride ingress into concrete: a comparative study. Materials and Structures, on line Octobre 2013, http://dx.doi.org/10.1617/s11527-013-0189-z 
Table 1. Average water intakes (in weight) determined at $20^{\circ} \mathrm{C}$

\begin{tabular}{|c|c|c|c|}
\hline Relative humidity & $60 \%$ & $80 \%$ & $90 \%$ \\
\hline $\begin{array}{c}\text { Massic water content } \\
\text { of the concrete }\end{array}$ & $3.08 \%$ & $3.36 \%$ & $3.88 \%$ \\
\hline $\begin{array}{c}\text { Volumetric water } \\
\text { content of the concrete }\end{array}$ & $6.78 \%$ & $7.39 \%$ & $8.54 \%$ \\
\hline
\end{tabular}

Table 2. Slopes and relative slopes determined through the investigations for the radar results

\begin{tabular}{|l|l|l|l|l|l|c|}
\hline & \multicolumn{2}{|l|}{$\begin{array}{l}\text { Amplitude } \\
(\text { direct wave })\end{array}$} & \multicolumn{2}{l|}{$\begin{array}{l}\text { Amplitude } \\
(\text { reflected wave })\end{array}$} & \multicolumn{2}{l|}{ Travel time } \\
\hline RH & $\begin{array}{l}\text { Slope } \\
\left(-/{ }^{\circ} \mathrm{C}\right)\end{array}$ & $\begin{array}{l}\text { Relative slope } \\
\left(\% /{ }^{\circ} \mathrm{C}\right)\end{array}$ & $\begin{array}{l}\text { Slope } \\
\left(-/{ }^{\circ} \mathrm{C}\right)\end{array}$ & $\begin{array}{l}\text { Relative slope } \\
\left(\% /{ }^{\circ} \mathrm{C}\right)\end{array}$ & $\begin{array}{l}\text { Slope } \\
\left(\mathrm{ns} /{ }^{\circ} \mathrm{C}\right)\end{array}$ & $\begin{array}{l}\text { Relative slope } \\
\left(\% /{ }^{\circ} \mathrm{C}\right)\end{array}$ \\
\hline $60 \%$ & -0.09 & -0.2 & -0.12 & -0.7 & 0.0017 & 0.1 \\
\hline $80 \%$ & -0.10 & -0.2 & -0.12 & -0.8 & 0.0018 & 0.1 \\
\hline $90 \%$ & -0.11 & -0.2 & -0.13 & -0.9 & 0.0021 & 0.1 \\
\hline
\end{tabular}

Table 3. Slopes and relative slopes determined through the investigations for the capacitive probe results

\begin{tabular}{|l|c|c|c|c|c|c|}
\hline & \multicolumn{2}{|l|}{ Permittivity for LE (-) } & \multicolumn{2}{l|}{ Permittivity for AE } & \multicolumn{2}{l|}{ Permittivity for SE } \\
\hline RH & $\begin{array}{l}\text { Slope } \\
\left(-/{ }^{\circ} \mathrm{C}\right)\end{array}$ & $\begin{array}{l}\text { Relative slope } \\
\left(\% /{ }^{\circ} \mathrm{C}\right)\end{array}$ & $\begin{array}{l}\text { Slope } \\
\left(-/{ }^{\circ} \mathrm{C}\right)\end{array}$ & $\begin{array}{l}\text { Relative slope } \\
\left(\% /{ }^{\circ} \mathrm{C}\right)\end{array}$ & $\begin{array}{l}\text { Slope } \\
\left(-/{ }^{\circ} \mathrm{C}\right)\end{array}$ & $\begin{array}{l}\text { Relative slope } \\
\left(\% /{ }^{\circ} \mathrm{C}\right)\end{array}$ \\
\hline $60 \%$ & 0.038 & 0.5 & 0.016 & 0.2 & 0.009 & 0.1 \\
\hline $80 \%$ & 0.041 & 0.5 & 0.023 & 0.3 & 0.014 & 0.2 \\
\hline $90 \%$ & 0.064 & 0.8 & 0.040 & 0.5 & 0.033 & 0.4 \\
\hline
\end{tabular}

Table 4. Comparison of the sensitivity to temperature of the two studied non destructive methods

\begin{tabular}{|c|c|c|c|}
\hline $\begin{array}{c}\text { Non destructive } \\
\text { method }\end{array}$ & $\begin{array}{c}\text { Radar } \\
\text { (propagation time) }\end{array}$ & $\begin{array}{c}\text { Capacitive } \\
\text { technique (RH=60 \%) }\end{array}$ & $\begin{array}{c}\text { Capacitive } \\
\text { technique (RH = 80 \%) }\end{array}$ \\
\hline $\begin{array}{c}\text { Measurement } \\
\text { variation for a } \\
\text { temperature variation } \\
\text { of } 10^{\circ} \mathrm{C}\end{array}$ & $2.5 \%$ & $6 \%$ & $9 \%$ \\
\hline
\end{tabular}


$-17-$ 
Figure 1. Scheme of the measurement program for one relative humidity

Figure 2. Photo of the used radar equipment

Figure 3. Example of radar profile obtained on slab B at $20^{\circ} \mathrm{C}$ and $60 \% \mathrm{RH}$

Figure 4. Radar results for the dynamic longitudinal profiles for the ratio of the amplitude of the direct wave propagated on the surface and the reflected wave on the wave propagated in the air depending on the temperature

Figure 5. Radar results of the longitudinal dynamic profiles for the travel time

Figure 6. Radar results for the longitudinal profiles for the ratio of the amplitude of the direct wave propagated on the surface of the slab on the wave propagated in the air depending on the relative humidity of the environment.

Figure 7. Photos of the capacitive probe system and of the three different associated electrodes

Figure 8. Experimental capacitive probe results of the calibration for the capacitive probe system

Figure 9. Capacitive probe results a) Observed variation for series of 120 measurements on a concrete slab on different points for a permittivity range of 0.18 ; b) Realized investigations on the influence of border effects on the determination of the permittivity

Figure 10. Capacitive probe results for the large electrodes

Figure 11. Capacitive probe results for the middle electrodes

Figure 12. Capacitive probe results for the small electrodes 
Figure 1. Scheme of the measurement program for one relative humidity

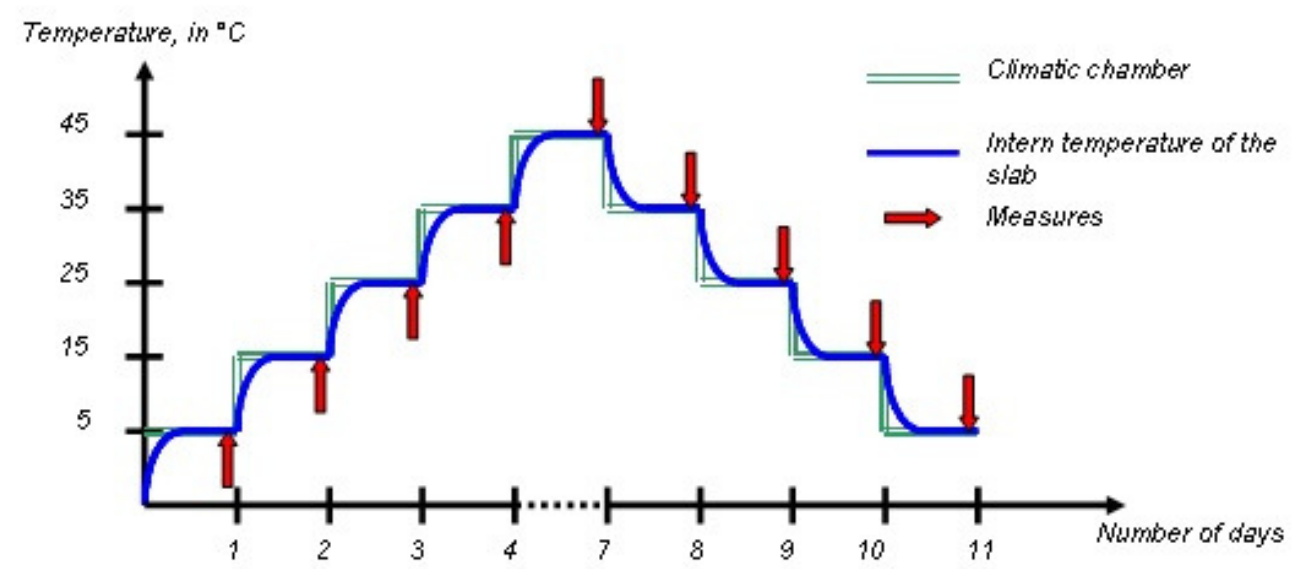


Figure 2. Photo of the used radar equipment

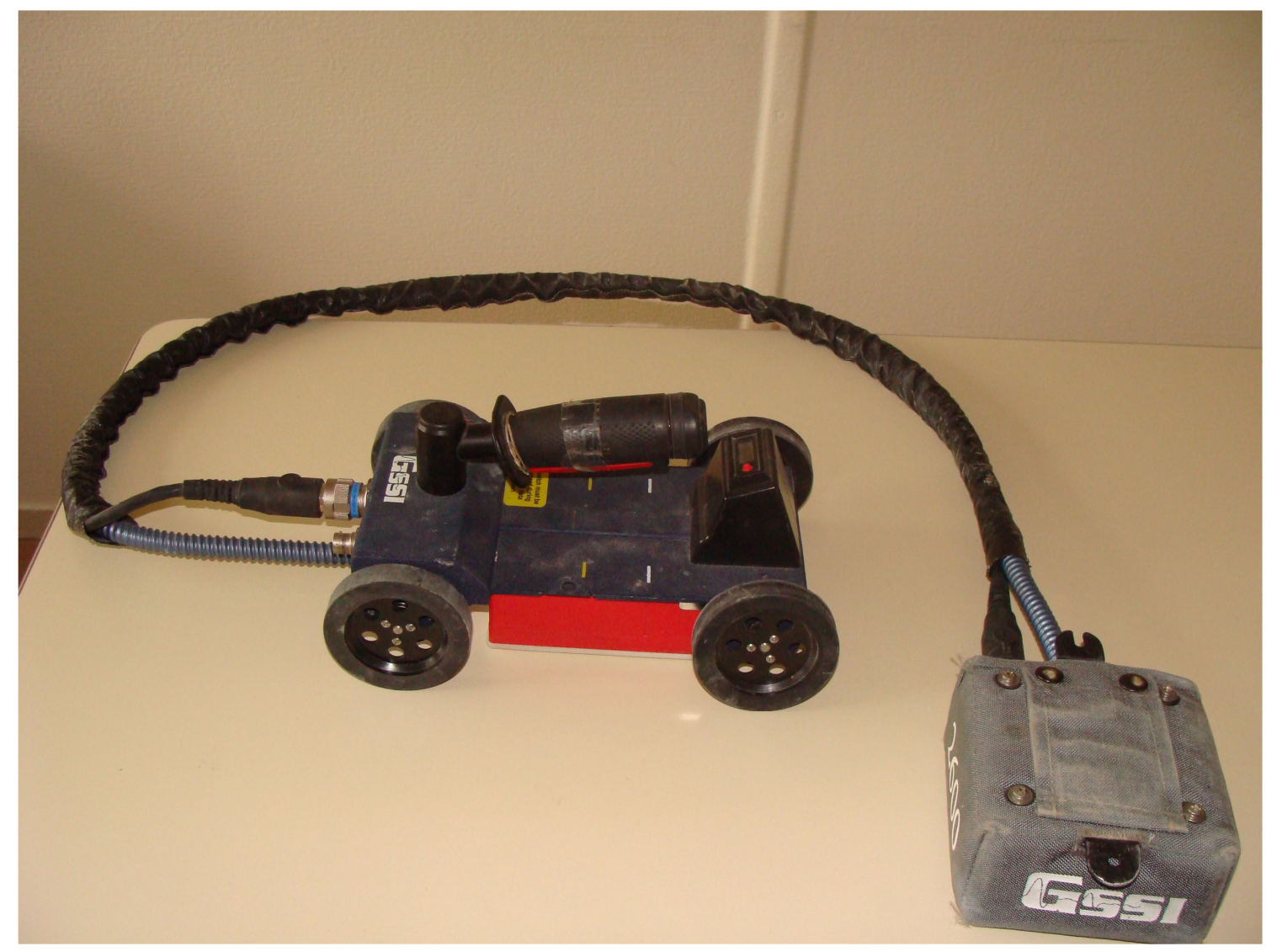


Figure 3. Example of radar profile obtained on slab B at $20^{\circ} \mathrm{C}$ and $60 \% \mathrm{RH}$

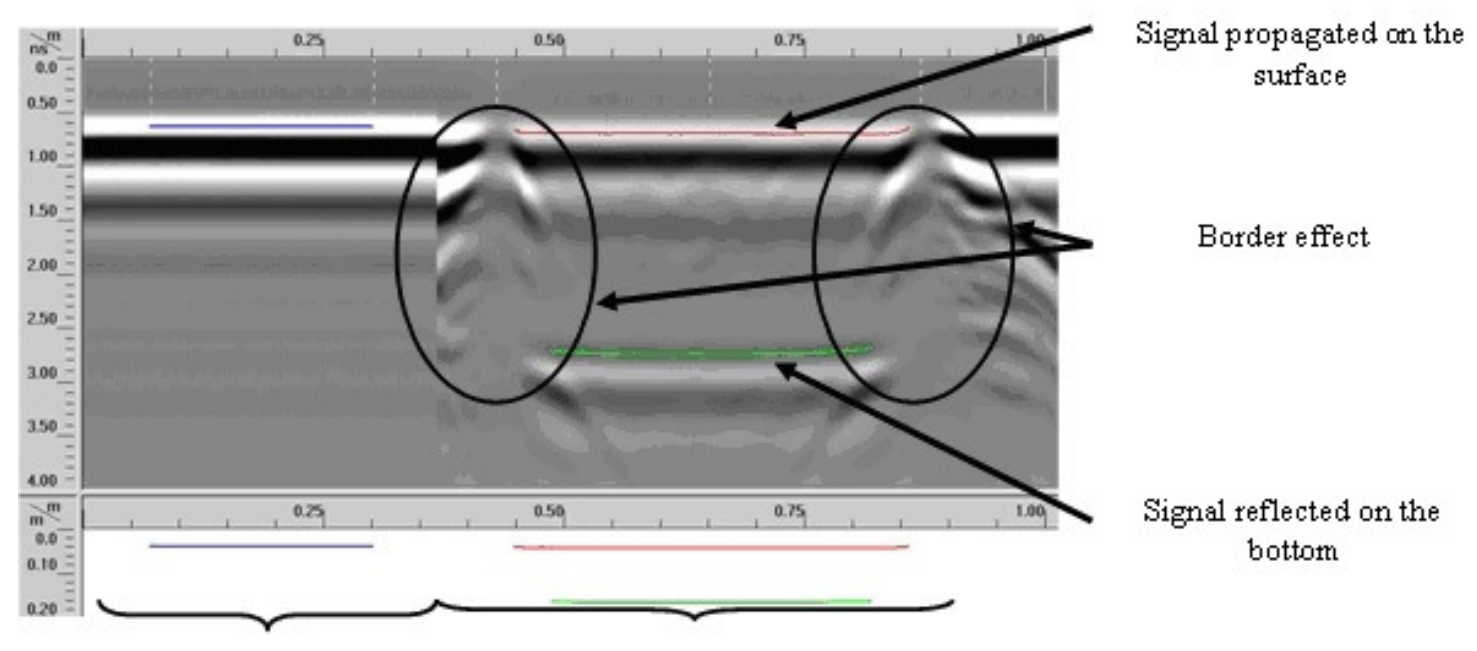


Figure 4. Radar results for the dynamic longitudinal profiles for the ratio of the amplitude of the direct wave propagated on the surface and the reflected wave on the wave propagated in the air depending on the temperature

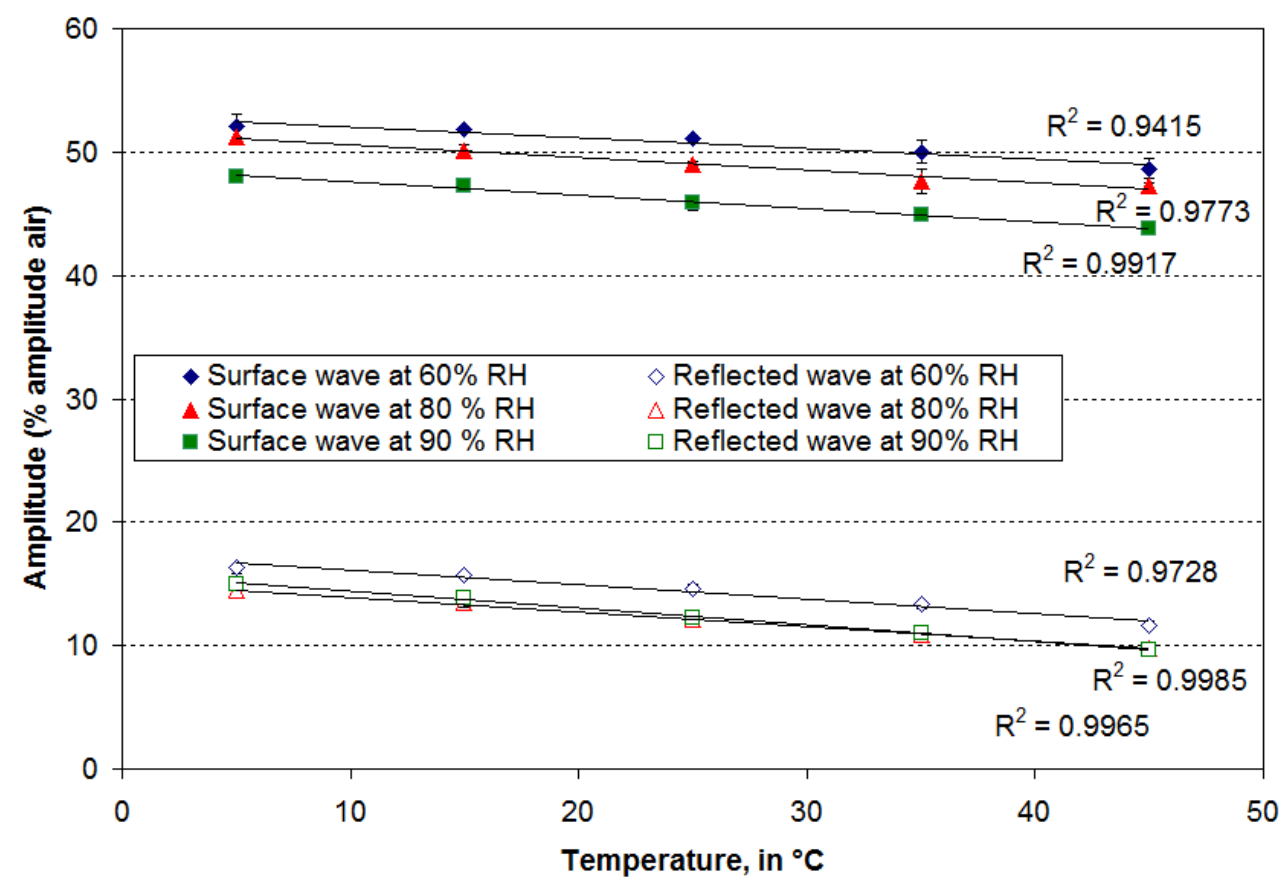


Figure 5. Radar results of the longitudinal dynamic profiles for the travel time

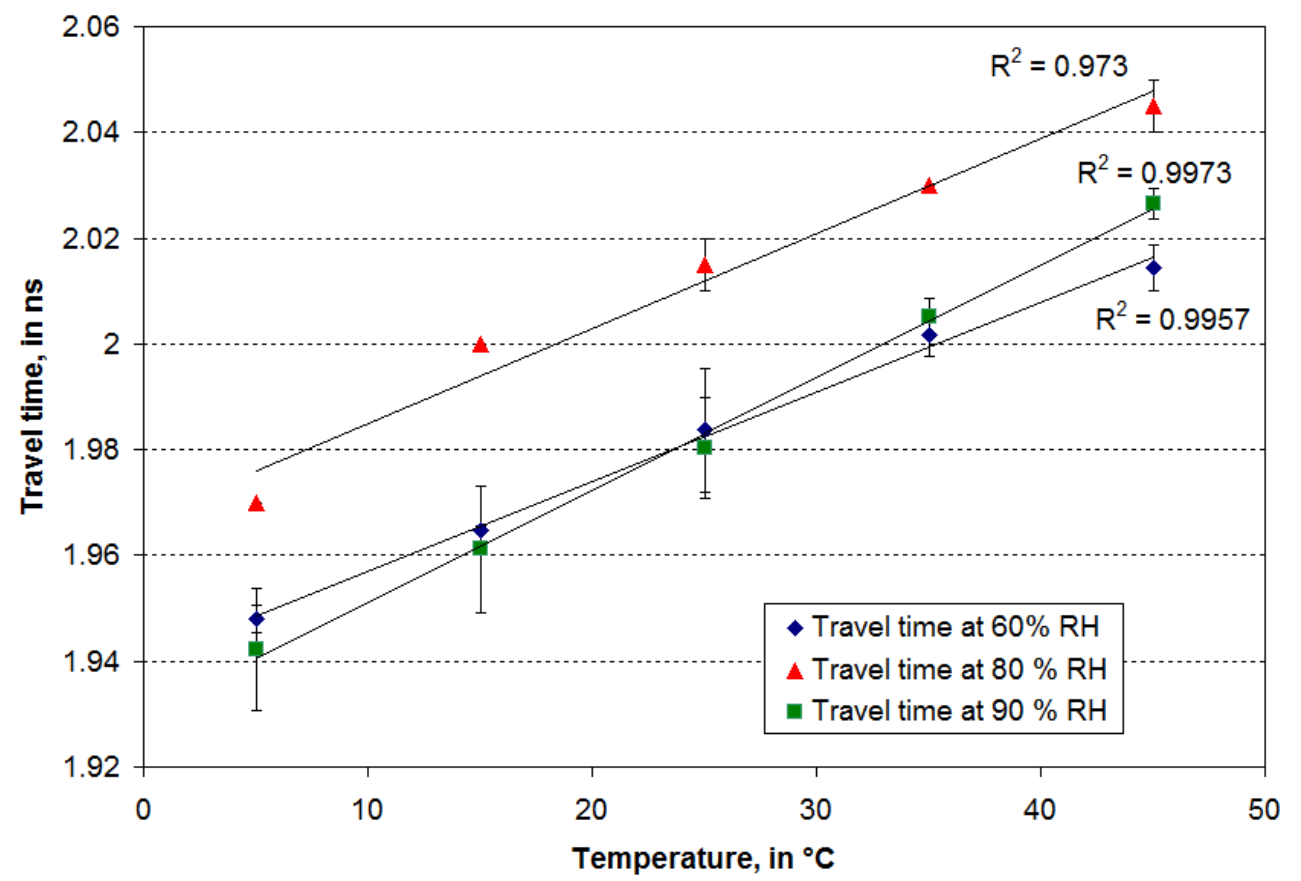


Figure 6. Radar results for the longitudinal profiles for the ratio of the amplitude of the direct wave propagated on the surface of the slab on the wave propagated in the air depending on the relative humidity of the environment.

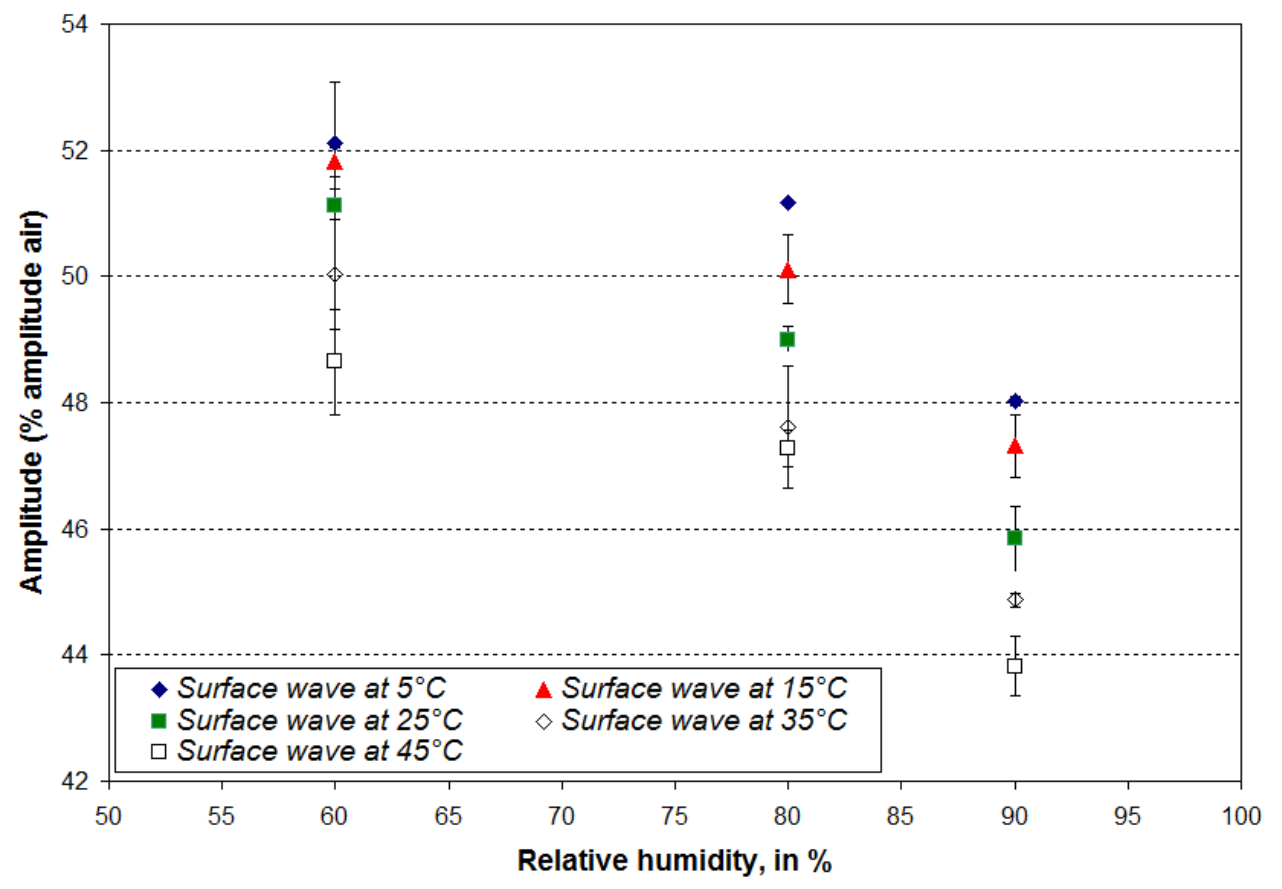


Figure 7. Photos of the capacitive probe system and of the three different associated electrodes
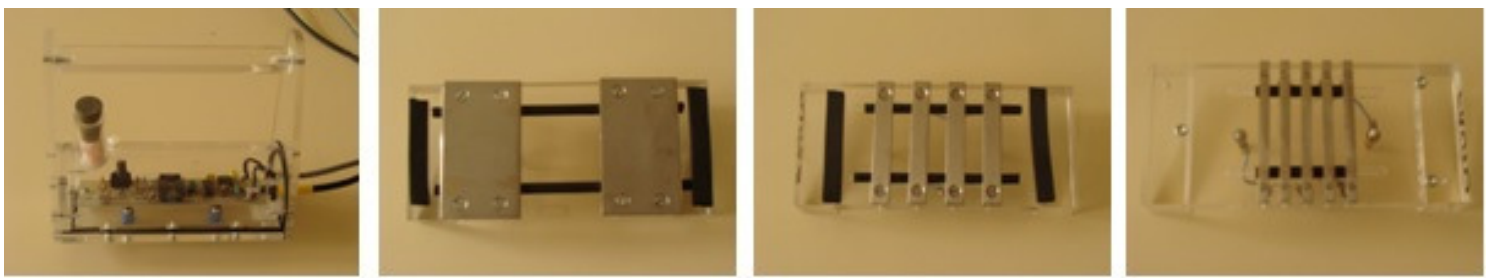
Figure 8. Experimental capacitive probe results of the calibration for the capacitive probe system

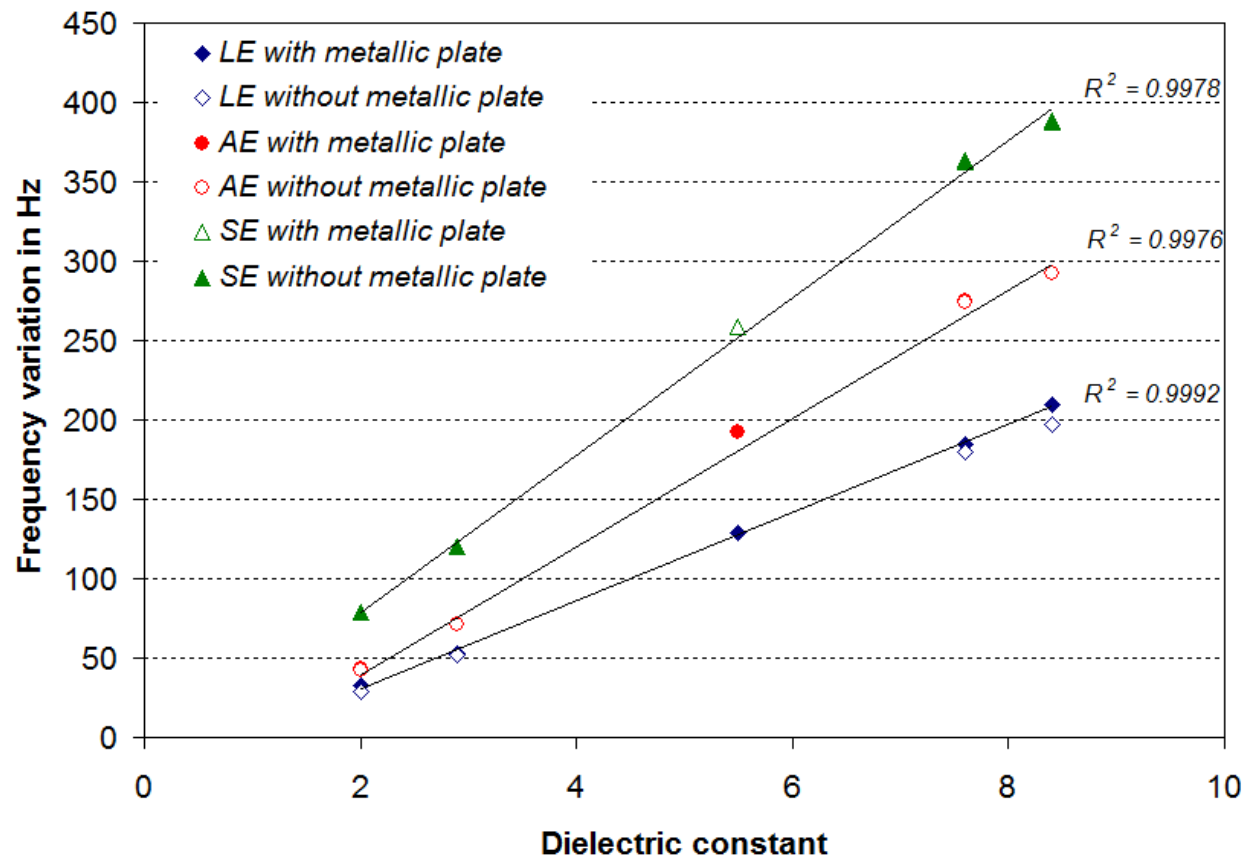


Figure 9. Capacitive probe results a) Observed variation for series of 120 measurements on a concrete slab on different points for a permittivity range of 0.18 ; b) Realized investigations on the influence of border effects on the determination of the permittivity
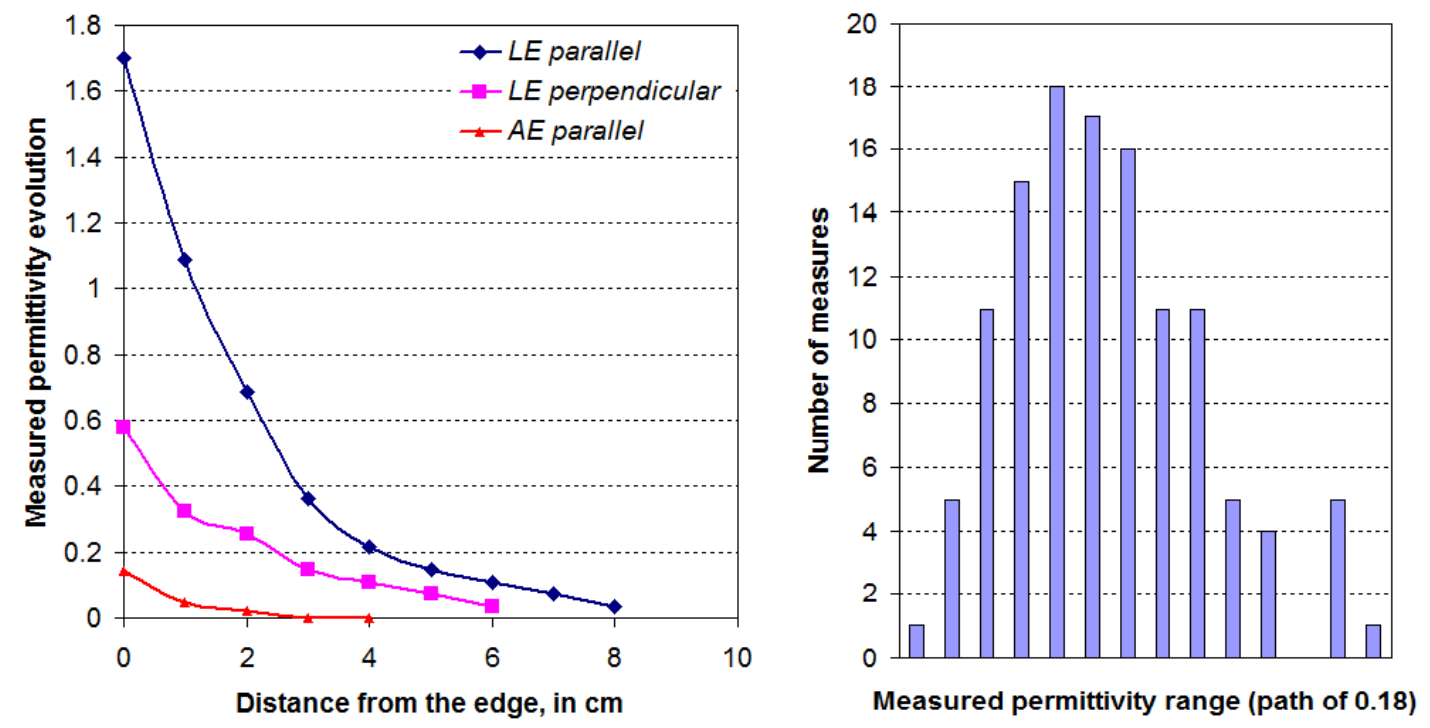
Figure 10. Capacitive probe results for the large electrodes

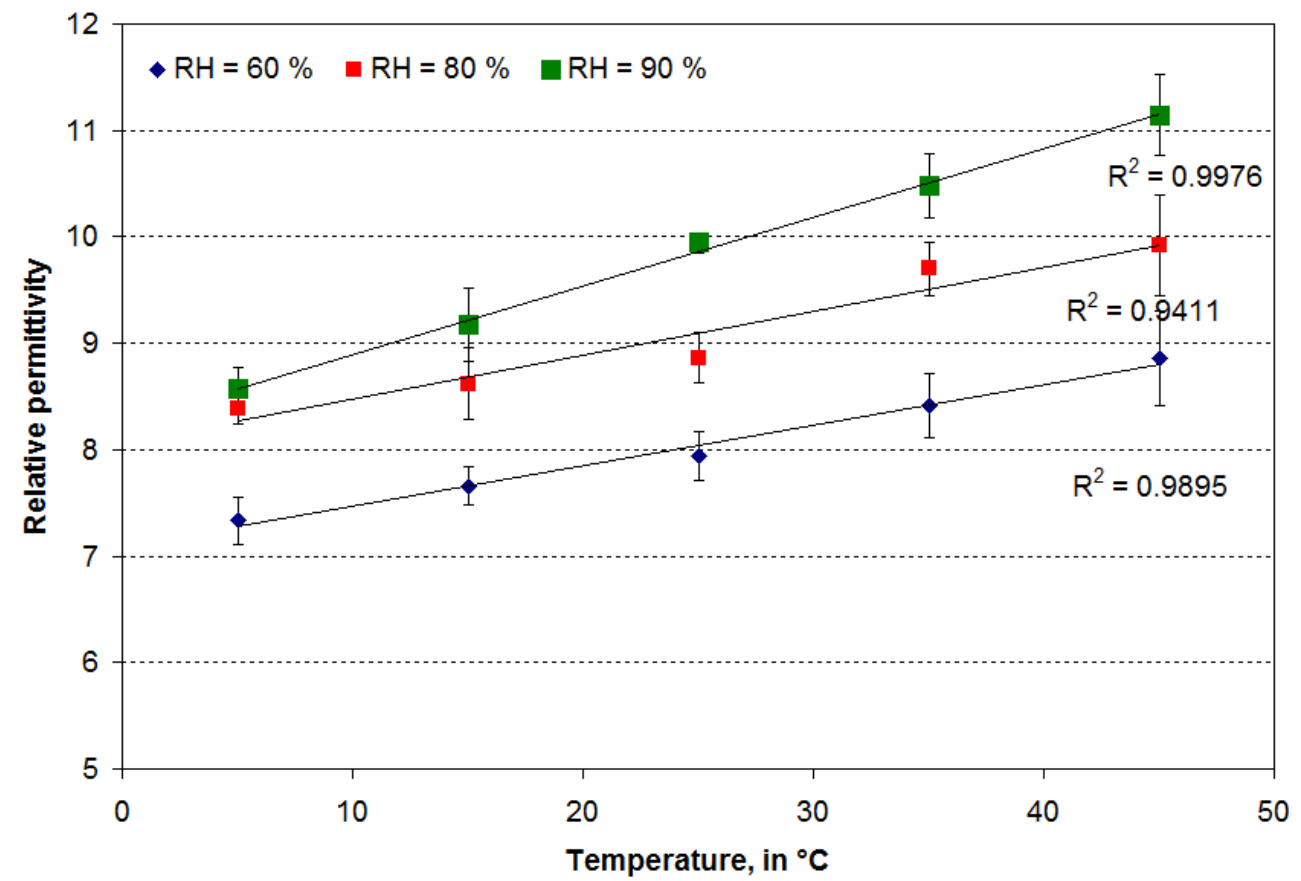


Figure 11. Capacitive probe results for the middle electrodes

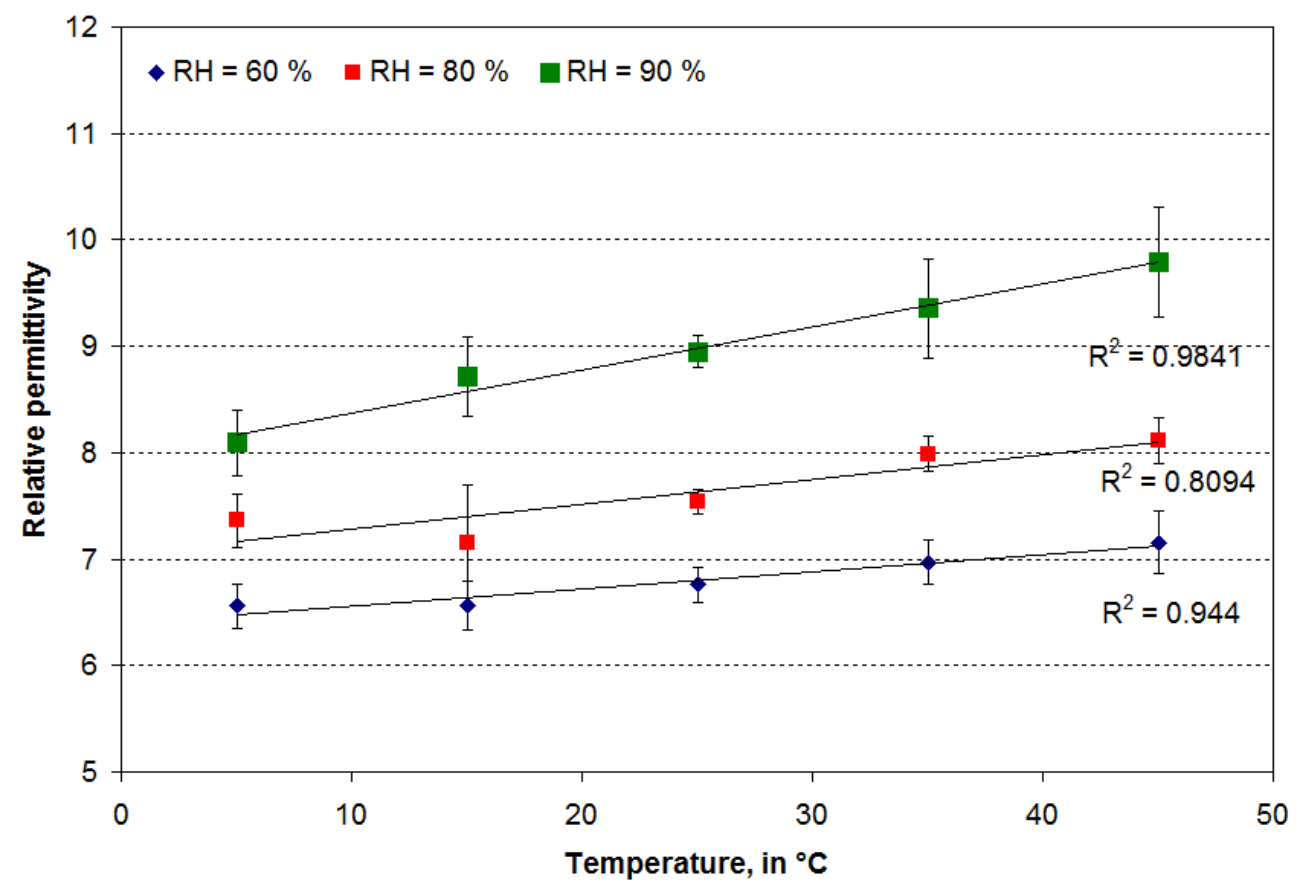


Figure 12. Capacitive probe results for the small electrodes

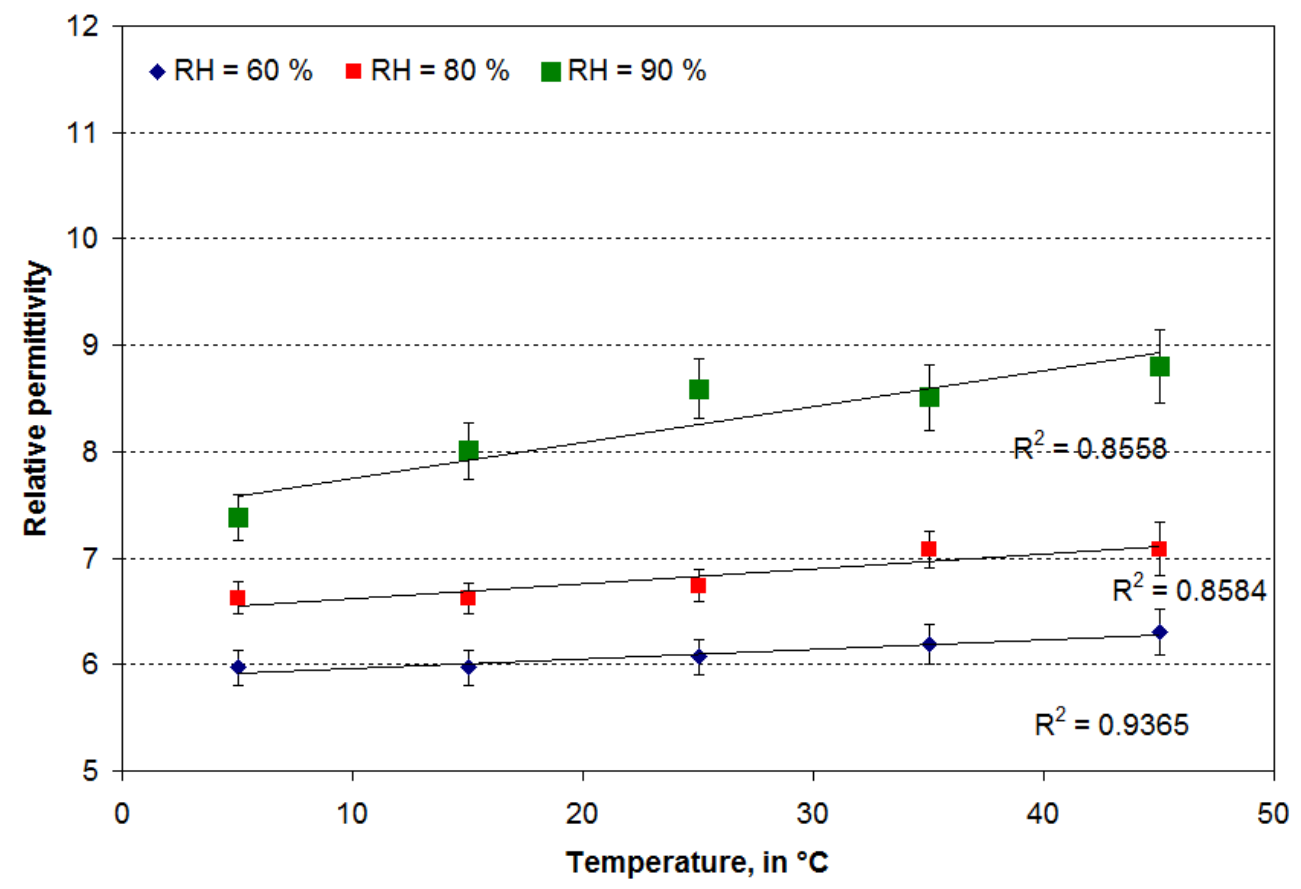

